\title{
Context-appropriate environmental attitude measurement in Nigeria using the Campbell paradigm
}

\author{
Charles A. Ogunbode ${ }^{1}$, Laura Henn ${ }^{2} \&$ Nicole Tausch ${ }^{3}$ \\ ${ }^{1}$ Department of Psychosocial Science, Faculty of Psychology, University of Bergen, Norway \\ ${ }^{2}$ Institut für Psychologie, Otto-von-Guericke Universität, Magdeburg, Germany \\ ${ }^{3}$ School of Psychology and Neuroscience, University of St Andrews, United Kingdom
}

Corresponding author:

Charles A. Ogunbode

Department of Psychosocial Science

Faculty of Psychology

University of Bergen

Postboks 7807

Christiesgate 12, Bergen 5020

Norway

Email: Charles.Ogunbode@uib.no

ORCID: 0000-0001-7566-5160

\section{Acknowledgements}

The preparation of this article was supported by a Santander Research Mobility Grant awarded to the first author. We thank Professor Florian Kaiser for helpful comments on an earlier draft of the manuscript.

\footnotetext{
Abstract

The need to tailor environmental policies in Africa with an understanding of public attitudes is commonly acknowledged, but efforts to generate such understanding are generally constrained by a lack of reliable context-appropriate measures. Attempts to 'borrow' Western measures in African research are typically undermined by the cross-cultural inequivalence of constructs and theoretical models. Consequently, we tested the potential of the Campbell paradigm - an approach that enables context-specific adaptation of attitude measurement, among a Nigerian sample $(N=543)$. Data were gathered with a questionnaire survey. Our findings show that a context-appropriate environmental attitude measure can be obtained by assessing the behaviours and intention statements Nigerians execute in response to environmental issues. On average, pro-environmental attitude levels among our sample was characterised by professed intentions to perform the most difficult behaviours and actual
} 
engagement in the least difficult behaviours. The environmental attitude measure derived using the Campbell paradigm is positively related to other conventional attitude indicators including the perceived threat of climate change, concern, efficacy beliefs and acceptance of responsibility for mitigation. We conclude that the Campbell paradigm offers a viable avenue to proceed beyond simple assessments of professed environmental attitudes to more accurate evaluations of Africans' disposition to strive for the achievement of ecological goals in difficult circumstances.

Keywords: attitude measurement, environmental attitudes, attitude-behaviour gap, Africa, cultural sensitivity

\section{Introduction}

The promotion of pro-environmental practices is a core objective of efforts to achieve ecological sustainability (Oskamp 2000; Hackmann et al. 2014). At the individual level, favourable attitudes toward environmental protection have been shown to be important determinants of pro-environmental actions (Kaiser et al. 1999; Marquart-Pyatt 2012). Thus, accurate assessments of environmental attitudes can be instrumental in promoting pro-environmental behaviour (Milfont and Duckitt 2004; Heberlein 2013).

This article addresses environmental attitude measurement among African populations. The impacts of climate change in Africa necessitate rapid development of effective communication, adaptation and mitigation strategies across the continent (Collier et al. 2008; Kumssa and Jones 2010). It is widely recognised that environmental policies and interventions need to be tailored with an understanding of public attitudes (Bryan et al. 2009; Shackleton et al. 2015). However, efforts to build such understanding in Africa are severely constrained by a lack of reliable context-appropriate measurement tools (BrowneNuñez and Jonker 2008). We addressed this constraint in the current study through an evaluation of the validity of the 'Campbell paradigm' (Kaiser et al. 2010) in an African context. Below, we present a brief review of theoretical and empirical research that substantiates the need to find contextually valid approaches to environmental attitude measurement in Africa with a focus on attitude research in Nigeria. Subsequently, we introduce the Campbell paradigm as an attitude measurement approach that 
could serve as a framework for assessing environmental attitude in Africa by allowing adaptation to diverse specific contexts.

\subsection{Environmental attitudes in Nigeria: A brief review of theoretical perspectives, empirical research and methodological challenges}

To date, adherence to ancient traditions such as taboos regarding wildlife exploitation and beliefs about the sanctity of forests helps protect the environment in parts of Africa (Mgumia and Oba 2003; Barre et al. 2009; Jimoh et al. 2012). This is often cited as evidence that indigenous African cultures inherently espouse ethics of environmental stewardship and harmony with nature (Ogungbemi 1997; Murove 2007; Behrens 2014). However, some authors have argued that the putative primacy of ecological concerns in Africa has been eroded by the cultural and institutional legacies of European colonization, alongside pressure from poverty and population growth (e.g., Adeola 1996). According to Fayemi (2016), contemporary practices in African countries are objectively inconsistent with philosophical portrayals of African environmental ethics as pro-ecological. Addressing the extreme rates of deforestation in Nigeria, Areola (2001) indicates that public attitudes are largely opposed to the sustenance of forest resources; as natural forest landscapes are seen to symbolize underdevelopment.

Although Nigeria faces various severe challenges arising from adverse environmental change, substantive environmental concern appears to be limited to an elite class of citizens with high socioeconomic status (Chokor 2004; Ifegbesan and Rampedi 2018). Where citizens of lower socioeconomic strata have reacted to local environmental problems (e.g., protesting environmental pollution arising from petroleum mining), ostensibly due to environmental concern, these actions are often born of broader social and political agitations rather than environmental motivations per se (Odoemene 2011; Iwilade 2012). Environmental attitudes in Nigeria are strongly utilitarian (Chokor 2004), and issues with obvious consequences for human wellbeing such as air pollution elicit greater public concern than less visible issues such as biodiversity loss (Ogunbode and Arnold 2012). Multiple studies using the New Ecological Paradigm (NEP) scale ${ }^{1}$ (Dunlap et al. 2000) have also documented

\footnotetext{
${ }^{1}$ The NEP scale was developed by an American environmental sociologist, Riley Dunlap, and is one of the most widely used measures of environmental concern in the world (see Dunlap 2008).
} 
predominantly anthropocentric environmental attitudes among Nigerian citizens (Ogunjinmi et al. 2012; Ogunbode 2013).

Attitude research in Africa operates on an assumption that attitudes are directly linked to behaviour (Browne-Nuñez and Jonker 2008). Thus, there is a demand for theoretical models that help explain the relationship between environmental behaviours and attitudes. Most environmental attitude studies conducted in Nigeria are not theory-driven, but some have 'borrowed' Western concepts and theories. For example, Ojedokun (2015) developed an ad hoc measure of attitudes toward littering in Nigeria based on a Western classical understanding of attitudes as comprising cognitive, affective and intentional aspects. Adopting Bandura's (1991) social cognitive theory, Ojedokun (2011a) showed that attitudes toward littering are significantly predicted by self-monitoring and self-efficacy, among other factors. Importantly, Ojedokun (2011b) also found that environmental attitudes mediate an indirect relationship between personality attributes and pro-environmental behaviour. Studies such as Ojedokun's (2011a, b) are valuable preliminary efforts in the development of a coherent structural understanding of environmental attitudes in Nigeria. However, accounting for the context-specific characteristics of general attitudes toward environmental issues in Nigeria, and other African societies, necessitates further search for holistic psychometric instruments that are demonstrably suited to the African cultural and experiential landscape (Ogunbode 2013).

The adaptability of Western research instruments to African populations is often undermined by the cross-cultural inequivalence of concepts and theoretical models (Browne-Nuñez and Jonker 2008). Scholars have previously observed that Western instruments may be incomprehensible or irrelevant to respondents in other cultures (Manson 1997). Unless the meaning and salience of the constructs being measured have been determined to be cross-culturally equivalent, applying Western instruments with African populations can lead to erroneous conclusions (Douglas and Nijssen 2003). The Campbell paradigm has potential to overcome the challenge of contextual specificities by representing the relationship between environmental attitudes and behaviour as axiomatic rather than causal. This concept of environmental attitude measurement rests on a notion that attitudes are implied by individuals' actions and verbal declarations, relative to the circumstances in which these performances 
are executed (Kaiser et al. 2010). The theoretical underpinnings of the Campbell paradigm are expatiated below.

\subsection{Attitude measurement using the Campbell paradigm}

Attitudes are unobservable hypothetical constructs about mental states that must be inferred from overt responses (Heberlein 2013). In the environmental domain, they are most commonly defined as a tripartite construct encompassing the beliefs, affect and action intentions that people express in response to environmental issues (Schultz et al. 2004). Of the three attitude components, intentions are understood to be most proximally linked to behaviour (Ajzen 1991). Yet, evident inconsistencies between people's professed intentions and their actual behaviour (termed the attitude-behaviour gap) have historically cast a shadow of doubt on the purported causal role of attitudes in the antecedence of behaviour (Ajzen and Fishbein 2005).

Campbell (1963) proposed that the attitude-behaviour gap is a consequence of the situational constraints that impinge on people's ability to act in accordance with their professed attitudes. According to Campbell, actions and verbal declarations regarding an issue or object arise from a common latent 'behavioural disposition', and incongruence between actual behaviour and professed intentions originate from the disregard of the relative difficulty of the different performances. For example, it is easier to profess support for reducing emissions by limiting personal car use than to give up driving for alternative forms of transport. In areas with poor public transport services, the difficulty of reducing car use may be so great that most people fail to act in line with their professed intentions to lower their carbon emissions from car use. In the absence of an account of behavioural difficulty, one would wrongly conclude that attitudes have no tangible link with behaviour in such scenarios. From Campbell's perspective, behavioural difficulty represents a situational threshold that must be overcome for attitudes (i.e. the latent behavioural disposition) to manifest as behaviour (Byrka 2009).

Decades after it was initially proposed, Campbell's idea has made a resurgence in psychology as a theoretical framework termed the 'Campbell paradigm' (Kaiser et al. 2010; Byrka and Kaiser 2013; Urban 2016). The Campbell paradigm conceptualizes the performance of a behaviour as a combined function of the situational threshold (behavioural difficulty or costs) associated with the realization of 
the behaviour and the level of a person's attitude or disposition to pursue the attitudinal goal reflected by the behaviour (Kaiser et al. 2010). The Campbell paradigm also posits that attitudes toward specific issues (e.g. environmental protection) can be deduced by assessing a set of actions implying the attitude in question, and that attitude strength can be inferred from the extent of difficulty that a person is willing to overcome in their pursuit of the goal implied by the attitude ${ }^{2}$. Below, we briefly discuss the fundamental principles of the Campbell paradigm with which we devised an environmental attitude measure in Nigeria.

\subsection{Fundamental principles of the Campbell paradigm}

\subsubsection{Attitudes are distinguished by sets of behavioural indicators}

The Campbell paradigm conceptualizes the relationship between attitude and behaviour as axiomatic rather than causal, i.e. attitude is understood as a latent disposition to act that is overtly manifested in its behavioural indicators (Kaiser et al. 2010). For example, pro-environmental attitude may be expressed through indicators such as voting for green political parties, purchasing an electric vehicle and indicating a degree of concern about environmental issues in surveys. Due to the indeterminacy of single behaviours (e.g., on its own, a decision to reduce meat consumption may be reflective of either environmental, health or financial motivations), accurate attitude inference must be achieved by assessing a set of verbal responses and actions implying the attitude in question. These actions constitute the behavioural means by which people realize their latent pro-environmental dispositions.

\subsubsection{Behavioural indicators are ranked in a transitive order of costs or difficulty}

Defining an attitude also depends on the order or structure of the behavioural indicators. Naturally, the performance of any given behaviour involves costs such as effort and time (Campbell 1963; Kaiser et al. 2010). These costs constitute the 'situational threshold' or difficulty of the behaviour. The costs of a behaviour are specific to the behaviour, and are largely independent of individuals, as they depend on the situation in which the behaviour takes place. Different actors approximately face the same costs

\footnotetext{
${ }^{2}$ For example, behaviours such as membership in an environmental group, recycling and green consumerism imply a pro-environmental attitude. Pro-environmental attitude in turn implies a degree of commitment to the goal of environmental protection.
} 
when they perform specific behaviours in the same sociocultural context (Kaiser et al. 2011). Therefore, the behavioural indicators of a given attitude can be ranked in a transitive order of costs or difficulty that is independent of actors. The specific transitive order of behaviours operates as a yardstick against which attitude is defined in a given context (Kaiser et al. 2010).

\subsubsection{Attitude level is reflected in the costs or difficulty of behavioural indicators}

Given a range of behavioural options, it is assumed that people choose to achieve their personal goals with cost-effective performances (Kaiser et al. 2010). This means that people will typically prefer to implement their attitudes with convenient, socially acceptable behaviours rather than more demanding or socially proscribed (i.e. costlier or more difficult) behaviours (Kaiser et al. 2011). The behavioural option(s) with which people elect to implement their attitude(s) is a combined function of the level of their commitment to the attitudinal goal and the specific difficulty of the behaviour(s) (i.e. the composite of costs involved in executing the performance). Therefore, the more difficulty an individual overcomes to implement their attitude, the more evident their commitment to the goal implied by the attitude (Kaiser et al. 2010).

Behavioural costs do not impose deterministically on people. Irregularities in attitude implementation often arise from unique life circumstances and individual differences in personal capabilities. Considering the complexity of modelling these irregularities, the Campbell paradigm aims to explain the probability of engagement in a behaviour rather than predict factual engagement (Kaiser et al. 2010).

\subsection{Operationalizing the Campbell paradigm}

The Campbell paradigm is operationalized with a probabilistic Rasch model instead of the deterministic Guttman model originally advocated by Campbell (1963). The Rasch model characterizes the probability of engaging in a specific behaviour as the difference between the level of an individual's attitude and the difficulty of the behaviour; with personal preferences and contextual irregularities handled as disturbance factors (Bond and Fox 2007; Kaiser et al. 2010). From this perspective, the link between a person's attitude and their probability of engaging in a specific behaviour is mathematically represented as: 


$$
\ln \left(\frac{p_{k i}}{1-p_{k i}}\right)=\theta_{k}-\delta_{i}
$$

where the natural logarithm of the ratio of the probability of person $k$ 's engagement $\left(p_{k i}\right)$ relative to the probability of non-engagement $\left(1-p_{k i}\right)$ in a specific behaviour $i$ is given by the difference between $k$ 's attitude level $\left(\theta_{k}\right)$ and the difficulty of the behaviour $\left(\delta_{i}\right)$ (Byrka 2009; Kaiser et al. 2010). In this mathematical representation, people are distinguishable with respect to their attitudes (regardless of the behavioural indicators considered in the measurement procedure), and behaviours are distinguishable by how difficult they are to realize (irrespective of the persons considered; Kaiser et al. 2013).

Logically, the validity of a Campbellian attitude measure depends on the extent to which its constituent behavioural indicators accurately reflect the target attitude. The appropriateness of indicators can vary between contexts due to geographic, infrastructural or cultural characteristics (Scheuthle et al. 2005). For example, while purchasing energy-efficient lightbulbs may be considered an appropriate indicator of pro-environmental attitude in Europe, it is a poor indicator in parts of Sub-Saharan Africa where the option to purchase energy-efficient lighting is unavailable to consumers. Thus, a measure of proenvironmental attitude must be constructed from indicators that suitably reflect a disposition to achieve pro-environmental goals in the respective context.

\subsection{Research goal}

The objective of this study was to assess environmental attitude in Nigeria using the Campbell paradigm. Based on the underlying principles of this approach, one can assume that appropriate environmental attitude measures are obtainable in any cultural context using a selection of behavioural indicators that (1) reflect pro-environmentalism among the given population and (2) can be ranked in a transitive order of difficulty. Therefore, pro-environmental attitude was assessed among a sample of Nigerians with climate change-related self-reported behaviours and intentions. We expected that (a) both self-reported actions and intentions regarding climate change arise from a single behavioural disposition (i.e. environmental attitude), and (b) that these environmental attitude indicators are ranked in a transitive order of difficulty; with the self-reported actions being generally more difficult than intention statements. Further, we expected to see a correlation between the difficulty of pro- 
environmental actions and their corresponding intention statements. In other words, (c) the differences in the difficulty of specific actions should be reflected both in intention formation and performance of the action. For example, this means that if reducing car use is more difficult than turning off lights in unoccupied rooms among a population, then intentions to reduce car use should be correspondingly more difficult than intentions to turn off lights in unoccupied rooms. Based on prior research showing that intentions to address climate change are significantly linked to perceived threat from climate change, concern, efficacy beliefs and acceptance of responsibility ${ }^{3}$ for mitigation action in Nigeria (Ogunbode and Arnold 2014), these constructs were used to test the convergent validity of the Campbellian environmental attitude measure.

\section{Method}

\subsection{Participants and procedure}

Six hundred questionnaires were administered to students within the main campus of the University of Ibadan with help from a research assistant in summer 2013. Respondents were recruited on a voluntary basis using a convenience sampling strategy and no reward was offered for participation in the study. 556 questionnaires were retrieved at the end of a six-week data collection period. Thirteen cases $(2.3 \%)$ were omitted due to incomplete data (> 50\% missing values) or problematic response patterns (e.g., giving the same response to consecutive questions irrespective of the direction of wording), leaving a final sample of $N=543$. A demographic breakdown of the sample is presented in Table 1. Ethical approval for the study was granted by the teaching and research ethics committee in the School of Psychology and Neuroscience, University of St Andrews ${ }^{4}$.

\subsection{Measures}

\subsubsection{Campbellian measure of pro-environmental attitude}

Environmental attitude was assessed with 18 self-reported behaviours and behavioural intentions (Table 1). Participants initially completed a 9-item scale of self-reported pro-environmental behaviours

\footnotetext{
${ }^{3}$ Although other authors commonly refer to this construct as 'ascription of responsibility' (e.g., Steg and de Groot 2010), the term 'acceptance of responsibility' is used here instead to more precisely describe the ascription of responsibility to oneself.

${ }^{4}$ There was no requirement to obtain ethics approval at the University of Ibadan as the research was conceived and administered at the University of St Andrews.
} 
spanning a broad range of difficulty. The choice of behaviours represented in the scale was based on their contextual appropriateness and relevance to climate change mitigation. Responses were recorded using a yes/no format and participants were advised to omit non-applicable items. In a subsequent section of the questionnaire, behavioural intentions were measured with 9 items matched with the selfreported pro-environmental behaviours. However, the intentions items were presented in a different order and prefaced with a question asking participants how likely they were to undertake the stated behaviours in future. Responses were recorded using a 7-point format ( $1=$ Not Likely, 7 = Very Likely).

\subsubsection{Convergence indicators}

Perceived threat $(\alpha=.86)$ was measured with a 6-item scale asking participants to indicate the extent to which they considered the effects of climate change a threat to their lifestyle, health, livelihood, family, community and Nigerian society (Ogunbode and Arnold 2014). Responses were recorded using a 7-point Likert format $(1=$ Strongly Disagree, 7 = Strongly Agree $)$.

Concern was measured by asking participants to rate the extent to which they feel concerned about the threat of climate change on a 7 -point scale $(1=$ Not at all, $7=$ Very Strongly $)$.

Efficacy beliefs $(\alpha=.87)$ were assessed with 8 items addressing participants' confidence in the effectiveness of personal and collective efforts to address climate change such as lifestyle changes and participation in environmental groups (see Supplementary File 1). Responses were recorded with a 7point format $(1=$ Not at all confident, $7=$ Very confident $)$.

Acceptance of responsibility ( $\alpha=.74$ ) was measured by participants' agreement with two items reflecting a sense of personal obligation to address climate change (see Supplementary File 1). Responses were recorded with a 7-point Likert format ( $1=$ Strongly Disagree, $7=$ Strongly Agree $)$.

\subsection{Data analysis}

The unidimensionality of the Campbellian pro-environmental attitude measure was tested with a simple dichotomous Rasch model using ConQuest version 4 (Adams et al. 2015). The simple dichotomous Rasch model estimates persons' attitude levels $\left(\theta_{k}\right)$ and the specific, person-independent difficulty of items $\left(\delta_{i}\right)$ using a maximum likelihood procedure (see Bond and Fox 2007). Mean square (MS) fit 
statistics (weighted by the item variance) were used to assess model fit. The weighted MS statistics indicate the deviation of the Rasch-modelled responses from the empirical data. Both item and person statistics are ideally expected to show a mean of weighted mean squares $M(\mathrm{MS})=0$. As a probabilistic model, the Rasch model tolerates some variation of mean squares. Deviations $>1$ indicate more variation than expected, while items with deviations $<1$ are more deterministic than expected. Threshold values of $0.7<\mathrm{MS}<1.3$ and standardized fit $|t| \leq 1.96$ are regarded as indicators of good item and person fit respectively (Wright and Linacre 1994). To reduce measurement error in item responses, responses to behavioural intentions items were dichotomized prior to analysis by collapsing options 1-4 into 'Not likely = 0' and options 5-7 into 'Likely = 1' (see Kaiser and Wilson 2000).

Pro-environmental attitude is represented by five plausible values (termed $\mathrm{EA}_{1}$ to $\mathrm{EA}_{5}$ ) randomly drawn for each person from the posterior distribution of Rasch-model-based estimates. This technique accounts for the uncertainty associated with probability-based estimations by reflecting other possible estimates for each person drawn from the same distribution with knowledge of the sample statistics (von Davier et al. 2009). Sample statistics (e.g., mean and standard deviation) provide a good approximation of sample characteristics but using only one 'observed' value per individual underestimates the true variability in the estimation. Therefore, five plausible values were used to test the convergence of the environmental attitude measure for more reliable results (see also Mislevy 1991; Adams et al. 2015). All statistics were calculated for each of the five plausible values and then averaged.

\section{Results}

The Campbellian measure of pro-environmental attitude had acceptable internal consistency $(\alpha=.79)$, and reliability as determined by the Rasch model estimate of person separation reliability (PSR $=.75$ ). The self-reported behaviours and intentions items showed a good fit to the Rasch model $(M[\mathrm{MS}]=.98$, $S D=.10)$ with fit estimates within the acceptable range $(0.7<\mathrm{MS}<1.3)$ which supports the expectation that the items and item order reflect a single latent dimension (Table 2). This latent dimension was interpreted as representing pro-environmental attitude. Using a threshold of $t \leq 1.96$ for acceptable person fit, we determined that the Rasch model accurately predicted the response patterns of $93.7 \%$ of individuals in the sample. 
Overall, the self-reported behaviours had higher difficulty estimates than behavioural intentions (Figure 1). The significance of this difference between the two categories of pro-environmental attitude indicators is shown by the absence of an overlap in the confidence intervals for the difficulty estimates of each of the self-reported behaviours and their corresponding intention statements (Figure 1). Furthermore, the rank order of behaviour difficulty was highly similar between self-reported behaviours and behavioural intentions as can be seen in the near-parallel slopes of the curves for behaviours and intentions in Figure 1. This is also evidenced statistically by the correlation of difficulties for the behavioural and intention statements of each of the nine pro-environmental actions (Spearman's $\rho=$ $.79, p=.011)$, which supports our second expectation.

Participants' pro-environmental attitude scores as measured with the Campbellian measure is expressed in logits (i.e. the natural logarithm of the odds ratio for positive to negative answers) with higher scores representing higher pro-environmental attitude. The distribution of pro-environmental attitude scores within the sample reflects a bi-modal cluster around an attitude level that corresponds with the difficulties of the least difficult behavioural items (item 5, 6, 7, 8 and 9) and the most difficult intention items (item 11, 12 and 13; see Figure 2). There were no significant differences in pro-environmental attitude for any of the five plausible values across gender, age categories or faculty of study (see Table $3)^{5}$.

Significant positive correlations were observed between pro-environmental attitude and the convergence indicators. Perceived threat from climate change was weakly associated with proenvironmental attitude, while concern, acceptance of responsibility and efficacy beliefs were moderately associated with pro-environmental attitude (Table 4). Regression analysis also showed that climate change concern, acceptance of responsibility and efficacy beliefs regarding climate changerelated behaviour significantly predicted all five plausible estimates of pro-environmental attitude (Table 5). However, perceived threat did not significantly predict pro-environmental attitude. Considering the significant zero-order correlation between perceived threat and pro-environmental

\footnotetext{
${ }^{5}$ An alternative coding of participants' academic discipline yields significant differences between those plausibly most and least exposed to environmental information (See supplementary File 2).
} 
attitude, it seems plausible that the link between these two factors may be mediated by concern, acceptance of responsibility and efficacy beliefs. The climate change-related beliefs explained approximately $15 \%$ of the variance in pro-environmental attitude on average.

Overall, the pro-environmental attitude measure derived with the Campbell paradigm showed a good level of reliability. As expected, the intention statements had lower difficulty estimates than selfreported behaviours, and there was a high correspondence of difficulty ranks within behaviours and intentions. These observations indicate that behavioural indicators vary in difficulty, according to their nature (e.g., membership in an environmental group is more difficult than reading information about environmental issues) and type (stating an intention is less difficult than performing the actual behaviour). Further, the Campbellian measure of pro-environmental attitude was positively related to constructs previously demonstrated to be predictors of climate change-related pro-environmental behaviour.

\section{Discussion}

The aim of this study was to test the potential of the Campbell paradigm as an approach to measuring environmental attitude in an African context. This aim is rooted in a proposition that a contextuallyappropriate measure of environmental attitude can be derived by examining the behaviours and intentions that Africans report in response to environmental issues. The results of the study show that both self-reported environmental behaviours and behavioural intentions map onto a single latent dimension which reflects pro-environmental attitude. Further, the selected set of indicators yielded a reliable measurement scale and difficulty estimates were obtained for each behavioural indicator using Rasch analysis. The convergent validity of the Campbellian pro-environmental attitude measure was supported by significant positive correlations with measures of perceived threat from climate change, concern, efficacy beliefs and acceptance of responsibility for climate change mitigation. The positive correlation of the convergence variables (except perceived threat that explained no significant incremental variance) with pro-environmental attitude was confirmed for the five plausible values which supports the stability of the findings. 


\subsection{Implications}

As expected, self-reported behaviours had higher difficulty estimates than intention statements; demonstrating the differential costs associated with stating an intention to perform a behaviour compared with actually performing the behaviour. In fact, every intention statement was easier than any of the behaviours, regardless of the content. More importantly, the average level of pro-environmental attitude among the sample was characterised by clusters of low difficulty actions and high difficulty intention statements; meaning that participants commonly overstated their intentions and underperformed with regard to actual environmental behaviour. This pattern epitomises the infamous intention-behaviour gap and echoes prior reports of incongruence between professed environmental values/attitudes and behaviour in Africa (e.g., Mtutu and Thondhlana 2016). It also challenges the common practice of depending solely on declarations of beliefs, worldviews or intentions as environmental attitude indicators; as these are low difficulty performances with limited capacity to reflect individuals' propensity to overcome substantial difficulty and costs in order to implement their pro-environmental attitudes (cf. Dunlap et al. 2000; Milfont and Duckitt 2010; Ojedokun 2015). In other words, professed beliefs, worldviews and intentions are incapable of discriminating between individuals with high levels of pro-environmental attitude and are therefore ineffective instruments for mapping the spectrum of motivation to achieve pro-environmental goals among a given population.

The magnitude of obstacles a person overcomes and the amount of effort they expend to implement their attitude signals their commitment to the goal implied by the attitude (Kaiser et al. 2010). A major benefit of the Campbell paradigm is that it enables direct estimation of the probability of individuals' engagement in pro-environmental practices. This means that assessing levels of environmental attitude using the Campbell paradigm also yields an indication of the probability that individuals in African societies will overcome high difficulty and costs to achieve environmental goals. For example, the current study shows that while the probability of professing an intention to join an environmental group was high $(\sim 50 \%)$ among the sample, the probability of actually performing this behaviour was very low (9\%) (Table 1; Figure 2). In this scenario, we can surmise that commitment to protecting the 
environment among most individuals in our sample lies at a level at which intentions to join or donate to an environmental group are easily formed but not readily translated into action.

Personal characteristics and social factors strongly modulate the correspondence between behaviour and professed attitudes (Tarrant and Cordell 1997; Olli et al. 2001). Although the Campbell paradigm offers a perspective on individuals' propensity to implement their pro-environmental attitude in the face of varying levels of behavioural costs and difficulty, it is unable to explain the circumstances that define the situational thresholds for engagement in specific environmental actions. As discussed in the introduction to this article, environmentally-damaging behaviours have traditionally been proscribed in Nigeria, and other parts of Africa, by social mechanisms (e.g., taboos). However, these mechanisms have become less effective as ever greater numbers of Nigerians abandon cultural beliefs that support environmental protection in favour of non-indigenous belief systems (Babalola et al. 2014). The upsurge in unsustainable practices following the decline of these social mechanisms arguably reflects a general lack of intrinsic commitment to the goal of environmental protection. Poor knowledge of environmental problems, particularly climate change, may also be a significant barrier to engagement in appropriate pro-environmental behaviours (Ajaps and McLellan 2015). A recent study revealed that over two-thirds of adults in several African countries, including Nigeria, have no awareness of climate change (Lee et al. 2015). Some authors have reported a positive link between environmental knowledge and engagement in pro-environmental behaviours in Nigeria (Ajaps and McLellan 2015). On this basis, it seems likely that raising public awareness of climate change and appropriate behavioural responses may prove to be an effective strategy for promoting pro-environmental attitudes and behaviour.

\subsection{Limitation}

This study has a limitation that can be addressed in subsequent research. The sample was entirely comprised of university students who may poorly represent the diversity of the wider Nigerian population. The relative homogeneity of social status among the sample was an advantage in the current study because it means that social status was, in effect, controlled for. However, considering other studies have shown that social status indicators such as occupation and education level have significant effects on environmental attitude in Nigeria (e.g., Ogunbode and Arnold 2012), it would be informative 
to determine if the distribution of pro-environmental attitude levels observed in this study replicates among a more diverse sample of the population.

\subsection{Recommendations}

Without external incentivization, the level of pro-environmental attitude observed among our sample is unlikely to be sufficient for securing a sustainable future for Nigeria and other similar African countries. Therefore, pro-environmental attitudes need to be considered a priority for research and intervention in these contexts. From a Campbellian perspective, engagement in pro-environmental actions is a function of motivation to pursue pro-environmental goals and the difficulty or situational thresholds associated with implementing the behaviours necessary to achieve these goals. Efforts to promote sustainability in African contexts will be aided by increasing individuals' motivation to act pro-environmentally or reducing the barriers to pro-environmental actions.

\section{Conclusion}

Pro-environmental attitudes reflect individuals' propensity to pursue ecological goals (Kaiser et al. 2017). Therefore, the Campbell paradigm represents an opportunity to proceed beyond simple assessments of professed environmental attitudes among African populations, and on to more accurate evaluations of Africans' disposition (or lack of) to strive for the achievement of ecological goals in difficult circumstances. This study demonstrates that the Campbell paradigm overcomes the problem of contextual inequivalence which undermines applications of other Western attitude models with African populations by enabling an inference of pro-environmental attitude levels from the behaviours and intention statements individuals execute in response to environmental problems. It should be noted that the appropriateness of indicators in the Campbellian environmental attitude measure is highly dependent on the sociocultural context. However, the 'specific-objectivity' of a Campbell-based measure means that different sets of indicators can measure the same construct in different contexts and attitude measurement need not be limited to a specific set of indicators (Kaiser et al. 2018). Hence, the Campbell paradigm enables accurate attitude measurement across different contexts by allowing contextual adaptation of the item content. 


\section{References}

Adams RJ, Wu ML, Wilson MR (2015) ACER ConQuest: Generalised item response modelling software

Adeola FO (1996) Environmental Contamination, Public Hygiene, and Human Health Concerns in the Third World: The Case Of Nigerian Environmentalism. Environ Behav 28:614-646. doi: $10.1177 / 001391659602800503$

Ajaps S, McLellan R (2015) "We don’t know enough": Environmental education and proenvironmental behaviour perceptions. Cogent Educ 2:

Ajzen I (1991) The theory of planned behavior. Organ Behav Hum Decis Process 50:179-211. doi: 10.1016/0749-5978(91)90020-T

Ajzen I, Fishbein M (2005) The influence of attitudes on behaviour. Handb Attitudes 173-221. doi: 10.1007/BF02294218

Areola O (2001) Deforestation in Nigeria: The pressures at the grassroots level. In: Vajpeyi DK (ed) Deforestation, Environment, and Sustainable Development: A Comparative Analysis. Praeger Press, Westport, pp 173-196

Bandura A (1991) Social cognitive theory of self-regulation. Organ Behav Hum Decis Process 50:248-287. doi: 10.1016/0749-5978(91)90022-L

Barre RY, Grant M, Draper D (2009) The role of taboos in conservation of sacred groves in Ghana's Tallensi-Nabdam district. Soc Cult Geogr 10:25-39. doi: 10.1080/14649360802553194

Behrens KG (2014) An African Relational Environmentalism and Moral Considerability. Environ Ethics 36:63-82. doi: 10.5840/enviroethics20143615

Bond TG, Fox CM (2007) Applying the Rasch Model: Fundamental Measurement in the Human Sciences. Lawrence Erlbaum Associates, Mahwah, NJ

Browne-Nuñez C, Jonker SA (2008) Attitudes toward wildlife and conservation across Africa: A review of survey research. Hum. Dimens. Wildl. 13:47-70

Bryan E, Deressa TT, Gbetibouo GA, Ringler C (2009) Adaptation to climate change in Ethiopia and South Africa: options and constraints. Environ Sci Policy 12:413-426. doi:

10.1016/j.envsci.2008.11.002

Byrka KK (2009) Attitude-behavior consistency: Campbell's paradigm in environmental and health domains. Technische Universiteit Eindhoven

Byrka KK, Kaiser FG (2013) Health performance of individuals within the Campbell paradigm. Int J 
Psychol 48:986-999. doi: 10.1080/00207594.2012.702215

Campbell DT (1963) Social attitudes and other acquired behavioral dispositions. In: Koch S (ed) Psychology: A study of a science. McGraw-Hill, New York, pp 94-172

Chokor BA (2004) Perception and response to the challenge of poverty and environmental resource degradation in rural Nigeria: Case study from the Niger Delta. J Environ Psychol 24:305-318. doi: 10.1016/j.jenvp.2004.08.001

Collier P, Conway G, Venables T (2008) Climate change and Africa. Oxford Rev Econ Policy 24:337-353. doi: 10.1093/oxrep/grn019

Douglas SP, Nijssen EJ (2003) On the use of "borrowed" scales in cross-national research: A cautionary note. Int Mark Rev 20:621-642. doi: 10.1108/02651330310505222

Dunlap RE (2008) The new environmental paradigm scale: From marginality to worldwide use. J Environ Educ

Dunlap RE, Van Liere KD, Mertig AG, Jones RE (2000) Measuring Endorsement of the New Ecological Paradigm : A Revised NEP Scale. J Soc Issues 56:425-442

Fayemi AK (2016) African Environmental Ethics and the Poverty of Eco-Activism in Nigeria. Matatu 48:363-388. doi: 10.1163/18757421-04802008

Hackmann H, Moser SC, St. Clair AL (2014) The Social Heart of Global Environmental Change. Nat Clim Chang 4:653-655. doi: 10.1038/nclimate2320

Heberlein TA (2013) Navigating Environmental Attitudes

Ifegbesan AP, Rampedi IT (2018) Understanding the role of socio-demographic and geographical location on pro-environmental behavior in Nigeria. Appl Environ Educ Commun 1-17

Iwilade A (2012) "Green" or "Red"? Reframing the environmental discourse in Nigeria. Africa Spectr 47:157-166

Jimoh SO, Ikyaagba ET, Alarape AA, et al (2012) The role of traditional laws and taboos in wildlife conservation in the Oban hill sector of Cross River National Park (CRNP), Nigeria. J Hum Ecol 39:209-220. doi: 10.1080/09709274.2012.11906513

Kaiser FG, Byrka KK, Hartig T (2010) Reviving Campbell's paradigm for attitude research. Personal Soc Psychol Rev 14:351-367

Kaiser FG, Hartig T, Brügger A, Duvier C (2011) Environmental Protection and Nature as Distinct Attitudinal Objects: An Application of the Campbell Paradigm. Environ Behav 45:369-398. doi: $10.1177 / 0013916511422444$ 
Kaiser FG, Merten M, Wetzel E (2018) How do we know we are measuring environmental attitude? Specific objectivity as the formal validation criterion for measures of latent attributes. J Environ Psychol 55:139-146

Kaiser FG, Wilson M (2000) Assessing people's general ecological behavior: A cross-cultural measure. J Appl Soc Psychol 30:952-978. doi: 10.1111/j.1559-1816.2000.tb02505.x

Kaiser FG, Wölfing S, Fuhrer U (1999) Environmental attitude and ecological behaviour. J Environ Psychol 19:1-19. doi: 10.1006/jevp.1998.0107

Kumssa A, Jones JF (2010) Climate change and human security in Africa. Int J Sustain Dev World Ecol 17:453-461. doi: 10.1080/13504509.2010.520453

Lee TM, Markowitz EM, Howe PD, et al (2015) Predictors of public climate change awareness and risk perception around the world. Nat Clim Chang 5:1014-1019. doi: 10.1038/nclimate2728

Manson SM (1997) Ethnographic methods, cultural context, and mental illness: Bridging different ways of knowing and experience. Ethos 25:249-258. doi: 10.1525/eth.1997.25.2.249

Marquart-Pyatt ST (2012) Explaining Environmental Activism Across Countries. Soc Nat Resour 25:683-699. doi: 10.1080/08941920.2011.625073

Mgumia FH, Oba G (2003) Potential role of sacred groves in biodiversity conservation in Tanzania. Environ Conserv 30:259-265. doi: 10.1017/S0376892903000250

Milfont TL, Duckitt J (2010) The environmental attitudes inventory: A valid and reliable measure to assess the structure of environmental attitudes. J Environ Psychol 30:80-94

Milfont TL, Duckitt J (2004) The structure of environmental attitudes: A first- and second-order confirmatory factor analysis. J Environ Psychol 24:289-303. doi: 10.1016/j.jenvp.2004.09.001

Mislevy RJ (1991) Randomization-based inference about latent variables from complex samples. Psychometrika 56:177-196. doi: 10.1007/BF02294457

Mtutu P, Thondhlana G (2016) Encouraging pro-environmental behaviour: Energy use and recycling at Rhodes University, South Africa. Habitat Int 53:142-150

Murove MF (2007) The Shona ethic of Ukama with reference to the immortality of values. Mankind Q 48:179-189

Odoemene A (2011) Social Consequences of Environmental Change in the Niger Delta of Nigeria. J Sustain Dev 4:123-135. doi: 10.5539/jsd.v4n2p123

Ogunbode CA (2013) The NEP Scale: Measuring ecological attitudes/worldviews in an African context. Environ Dev Sustain 15:1477-1494 
Ogunbode CA, Arnold K (2012) A study of environmental awareness and attitudes in Ibadan, Nigeria. Hum Ecol Risk Assess 18:669-684. doi: 10.1080/10807039.2012.672901

Ogunbode CA, Arnold K (2014) Knowledge, morality, and threat perception: A juxtaposition of internal influences on climate change-related behavioral intentions in Nigeria. Hum Ecol Risk Assess 20:242-262. doi: 10.1080/10807039.2012.729141

Ogungbemi S (1997) An African perspective on the environmental crisis. In: Pojman L (ed) Environmental ethics: Readings in theory and application. Wadsworth Publishing, Belmont, pp $330-337$

Ogunjinmi AA, Onadeko SA, Adewumi AA (2012) An empirical study of the effects of personal factors on environmental attitudes of local communities around Nigeria's protected areas. J. Transdiscipl. Environ. Stud. 11:40-53

Ojedokun O (2011a) Psychosocial Analysis of Environmental Attitudeof Residents in a Nigerian Urban City. African J Basic Appl Sci 3:182-189

Ojedokun O (2015) The littering attitude scale (LAS). Manag Environ Qual An Int J 26:552-565. doi: 10.1108/MEQ-12-2014-0175

Ojedokun O (2011b) Attitude towards littering as a mediator of the relationship between personality attributes and responsible environmental behavior. Waste Manag 31:2601-2611. doi: 10.1016/j.wasman.2011.08.014

Olli E, Grendstad G, Wollebaek D (2001) Correlates of Environmental Behaviors: Bringing Back Social Context. Environ Behav 33:181-208. doi: 10.1177/0013916501332002

Oskamp S (2000) Psychological contributions to achieving an ecologically sustainable future for humanity. J Soc Issues 56:373-390

Scheuthle H, Carabias-Hütter V, Kaiser FG (2005) The motivational and instantaneous behavior effects of contexts: Steps toward a theory of goal-directed behavior. J Appl Soc Psychol 35:2076-2093. doi: 10.1111/j.1559-1816.2005.tb02210.x

Schultz PW, Shriver C, Tabanico JJ, Khazian AM (2004) Implicit connections with nature. J Environ Psychol 24:31-42. doi: 10.1016/S0272-4944(03)00022-7

Shackleton S, Ziervogel G, Sallu S, et al (2015) Why is socially-just climate change adaptation in subSaharan Africa so challenging? A review of barriers identified from empirical cases. Wiley Interdiscip Rev Clim Chang 6:321-344. doi: 10.1002/wcc.335

Steg L, de Groot J (2010) Explaining prosocial intentions: testing causal relationships in the norm activation model. Br J Soc Psychol 49:725-43. doi: 10.1348/014466609X477745 
Tarrant MA, Cordell HK (1997) The effect of respondent characteristics on general environmental attitude-behavior correspondence. Environ Behav 29:618-637

Urban J (2016) Are we measuring concern about global climate change correctly? Testing a novel measurement approach with the data from 28 countries. Clim Change 139:397-411. doi: 10.1007/s10584-016-1812-0

von Davier M, Gonzalez EJ, Mislevy RJ (2009) What are plausible values and why are they useful? IERI Monogr Ser Issues Methodol large-scale assessments 2:9-36

Wright BD, Linacre JM (1994) Reasonable mean-square fit values. Rasch Meas Trans 8:370 
Table 1. Demographic profile of the sample

\begin{tabular}{|c|c|c|c|}
\hline & & Frequency & Percent \\
\hline \multirow[t]{4}{*}{ Gender } & Male & 240 & 44.2 \\
\hline & Female & 266 & 49.0 \\
\hline & Total & 506 & 93.2 \\
\hline & Missing & 37 & 6.8 \\
\hline \multirow[t]{8}{*}{ Age } & $16-18$ & 120 & 22.1 \\
\hline & $19-21$ & 177 & 32.6 \\
\hline & $22-25$ & 140 & 25.8 \\
\hline & $26-30$ & 51 & 9.4 \\
\hline & $30-35$ & 32 & 5.9 \\
\hline & $>35$ & 14 & 2.6 \\
\hline & Total & 534 & 98.3 \\
\hline & Missing & 9 & 1.7 \\
\hline \multirow[t]{9}{*}{$\begin{array}{l}\text { Disciplines } \\
\text { represented }\end{array}$} & $\begin{array}{l}\text { Agriculture, Forestry \& Vet. } \\
\text { Medicine }\end{array}$ & 45 & 8.3 \\
\hline & Social Sciences \& Law & 125 & 23.0 \\
\hline & $\begin{array}{l}\text { Pharmacy, Medicine \& } \\
\text { Medical sciences }\end{array}$ & 43 & 7.9 \\
\hline & Arts \& Humanities & 44 & 8.1 \\
\hline & Pure Sciences & 129 & 23.8 \\
\hline & Education & 50 & 9.2 \\
\hline & Engineering \& Technology & 25 & 4.6 \\
\hline & Total & 461 & 84.9 \\
\hline & Missing & 82 & 15.1 \\
\hline
\end{tabular}


Table 2. Difficulty and fit estimates for items comprising the Campbellian measure of proenvironmental attitude

\begin{tabular}{|c|c|c|c|}
\hline Items & $\delta$ & $p$ & MS \\
\hline \multicolumn{4}{|l|}{ Self-reported behaviors } \\
\hline 1. Membership in an environmental group & 2.19 & .09 & 0.97 \\
\hline $\begin{array}{l}\text { 2. Contributed money to or volunteered in an environmental } \\
\text { organization }\end{array}$ & 1.23 & .21 & 1.10 \\
\hline $\begin{array}{l}\text { 3. Attended a climate change or environment-related seminar or } \\
\text { workshop }\end{array}$ & 1.11 & .23 & 1.06 \\
\hline 4. Participated in an environmental sensitization campaign or rally & 1.04 & .24 & 1.00 \\
\hline 5. Chosen or avoided a product because of its environmental impact & 0.40 & .37 & 1.13 \\
\hline $\begin{array}{l}\text { 6. Looked for information about climate change in books, magazines } \\
\text { or websites }\end{array}$ & 0.24 & .41 & 1.00 \\
\hline $\begin{array}{l}\text { 7. Talked to friends/relatives about climate change or other } \\
\text { environmental issues }\end{array}$ & 0.09 & .45 & 1.09 \\
\hline $\begin{array}{l}\text { 8. Tried to do things in ways that reduce personal impact on the } \\
\text { environment }\end{array}$ & 0.09 & .45 & 0.96 \\
\hline 9. Changed any aspect of lifestyle because of an environmental issue & 0.01 & .47 & 1.06 \\
\hline \multicolumn{4}{|l|}{ Behavioral intentions } \\
\hline 10. Join an environmental group & -0.07 & .49 & 0.96 \\
\hline 11. Take part in an environmental sensitization campaign & -0.30 & .54 & 0.91 \\
\hline $\begin{array}{l}\text { 12. Contribute money to or volunteer in an environmental } \\
\text { organization }\end{array}$ & -0.37 & .56 & 0.96 \\
\hline 13. Attend a climate change workshop or seminar & -0.38 & .56 & 0.89 \\
\hline $\begin{array}{l}\text { 14. Talk to friends and relatives about climate change and other } \\
\text { environmental issues }\end{array}$ & -0.80 & .66 & 0.92 \\
\hline $\begin{array}{l}\text { 15. Stop buying/using products that have a negative impact on the } \\
\text { environment }\end{array}$ & -0.97 & .70 & 1.05 \\
\hline 16. Take up a climate friendly lifestyle & -1.15 & .74 & 0.94 \\
\hline $\begin{array}{l}\text { 17. Try to learn more about climate change from books, the internet } \\
\text { and television }\end{array}$ & -1.17 & .74 & 0.93 \\
\hline $\begin{array}{l}\text { 18. Try to do more things that minimize personal environmental } \\
\text { impact }\end{array}$ & -1.17 & .74 & 1.04 \\
\hline
\end{tabular}

Note: Items are presented in order of decreasing difficulty. Item difficulties $(\delta)$ are expressed in logits; higher positive logit values represent higher difficulty. Logits represent the natural logarithm of the engagement/nonengagement probability ratio. Mean square (MS) values are weighted by item variance. $p$ represents the engagement likelihood for a person with an average environmental attitude level. 
Table 3. Differences across gender, age category, and faculty of study for five plausible values of proenvironmental attitude.

\begin{tabular}{lccccccc}
\hline & \multicolumn{2}{c}{ Gender } & \multicolumn{2}{c}{ Age category $^{\mathrm{a}}$} & \multicolumn{2}{c}{ Faculty of study } \\
\cline { 2 - 8 } & $M_{\text {male }}(S D)$ & $M_{\text {female }}(S D)$ & $p$ & $F_{(5,533)}$ & $p$ & $F_{(6,460)}$ & $p$ \\
\cline { 2 - 8 } $\mathrm{EA}_{1}$ & $-0.109(1.120)$ & $-0.154(1.013)$ & .635 & 0.405 & .846 & 0.736 & .621 \\
$\mathrm{EA}_{2}$ & $-0.096(1.133)$ & $-0.141(0.997)$ & .637 & 1.176 & .320 & 1.561 & .157 \\
$\mathrm{EA}_{3}$ & $-0.171(1.037)$ & $-0.205(1.013)$ & .704 & 0.576 & .718 & 1.953 & .071 \\
$\mathrm{EA}_{4}$ & $-0.139(1.096)$ & $-0.215(0.988)$ & .410 & 1.083 & .369 & 2.033 & .060 \\
EA $_{5}$ & $-0.142(1.072)$ & $-0.228(0.990)$ & .353 & 0.170 & .973 & 0.801 & .570 \\
\hline
\end{tabular}

Notes. EA = Pro-environmental attitude.

${ }^{\mathrm{a}}$ Age categories were coded as $1=16-18(N=120), 2=19-21(N=177), 3=22-25(N=140), 4=26-$ $30(N=51), 5=30-35(N=32), 6 \geq 35(N=14)$.

Table 4. Descriptive statistics and zero-order correlations for pro-environmental attitude and convergence indicators

\begin{tabular}{lccccc}
\hline & $\mathrm{M}(\mathrm{SD})$ & $\mathrm{PT}$ & Concern & AR & EB \\
\cline { 2 - 6 } $\mathrm{EA}_{1}$ & $-0.12(1.07)$ & .15 & .28 & .29 & .28 \\
$\mathrm{EA}_{2}$ & $-0.11(1.06)$ & .19 & .25 & .28 & .26 \\
$\mathrm{EA}_{3}$ & $-0.17(1.03)$ & .17 & .29 & .31 & .31 \\
$\mathrm{EA}_{4}$ & $-0.17(1.04)$ & .17 & .27 & .33 & .32 \\
$\mathrm{EA}_{5}$ & $-0.19(1.03)$ & .17 & .28 & .31 & .32 \\
Perceived Threat & $4.06(1.22)$ & .86 & .39 & .20 & .20 \\
Concern & $4.33(1.67)$ & & - & .31 & .27 \\
Acceptance of Responsibility & $4.30(1.54)$ & & & .74 & .46 \\
Efficacy Beliefs & $4.71(1.20)$ & & & & .87 \\
\hline
\end{tabular}

Notes. Correlations are Pearson's coefficients, all significant at $p<.001$ (2-tailed). Values in italics on the diagonal in the lower part are Cronbach's alpha for convergence indicators (no reliability is reported for concern because it was measured with a single item). Listwise valid $N=509$. PT $=$ Perceived threat, AR $=$ Acceptance of responsibility, EB = Efficacy beliefs, EA = Pro-environmental attitude. 
Table 5. Five plausible estimates of pro-environmental attitude regressed on threat, concern, acceptance of responsibility and efficacy beliefs.

\begin{tabular}{ccccccccccccc}
\hline & $\begin{array}{c}\text { Perceived } \\
\text { Threat }\end{array}$ & \multicolumn{1}{c}{ Concern } & \multicolumn{2}{c}{ AR } & \multicolumn{2}{c}{$\begin{array}{c}\text { Efficacy } \\
\text { beliefs }\end{array}$} & \multicolumn{2}{c}{ Constant } & \multicolumn{2}{c}{ Model Fit } \\
\hline $\mathrm{DV}$ & $B$ & $p$ & $B$ & $p$ & $B$ & $p$ & $B$ & $p$ & $B$ & $p$ & $F_{(4,508)}$ & Adj. $R^{2}$ \\
& $(S E)$ & & $(S E)$ & & $(S E)$ & & $(S E)$ & & $(S E)$ & & & \\
\hline $\mathrm{EA}_{1}$ & .02 & .645 & .11 & $<.001$ & .11 & $<.001$ & .14 & $<.001$ & -1.84 & $<.001$ & 21.12 & .137 \\
& $(.04)$ & & $(.03)$ & & $(.03)$ & & $(.04)$ & & $(.22)$ & & & \\
$\mathrm{EA}_{2}$ & .07 & .063 & .08 & .007 & .11 & $<.001$ & .12 & .005 & -1.82 & $<.001$ & 18.42 & .121 \\
& $(.04)$ & & $(.03)$ & & $(.03)$ & & $(.04)$ & & $(.22)$ & & & \\
$\mathrm{EA}_{3}$ & .03 & .384 & .11 & $<.001$ & .11 & $<.001$ & .16 & $<.001$ & -2.00 & $<.001$ & 24.44 & .156 \\
& $(.04)$ & & $(.03)$ & & $(.03)$ & & $(.04)$ & & $(.21)$ & & & \\
$\mathrm{EA}_{4}$ & .03 & .362 & .09 & $<.001$ & .13 & $<.001$ & .16 & $<.001$ & -2.05 & $<.001$ & 25.83 & .164 \\
& $. .04)$ & & $(.03)$ & & $(.03)$ & & $(.04)$ & & $(.21)$ & & & \\
$\mathrm{EA}_{5}$ & .03 & .372 & .10 & $<.001$ & .11 & $<.001$ & .17 & $<.001$ & -2.03 & $<.001$ & 24.45 & .156 \\
& $(.04)$ & & $(.03)$ & & $(.03)$ & & $(.04)$ & & $(.21)$ & & & \\
& & & & & & & & & & & & \\
Mean & .04 & $n . s$ & .10 & $<.01$ & .11 & $<.01$ & .15 & $<.01$ & -1.95 & $<.001$ & & .147 \\
$(S D)$ & $(.02)$ & & $(.04)$ & & $(.01)$ & & $(.02)$ & & $(.11)$ & & & $(.018)$ \\
\hline
\end{tabular}

Notes. All five models are significant at $p<.001 ; N=509$. Regression coefficients (B) and explained variance $\left(A d j . R^{2}\right)$ from all five models are averaged in the last row $(S D=$ Standard deviation across five parameters respectively; significant $p$-values are summarized by most conservative estimate). AR = Acceptance of responsibility, $\mathrm{DV}=$ Dependent variable, $\mathrm{EA}=$ Pro-environmental attitude. 


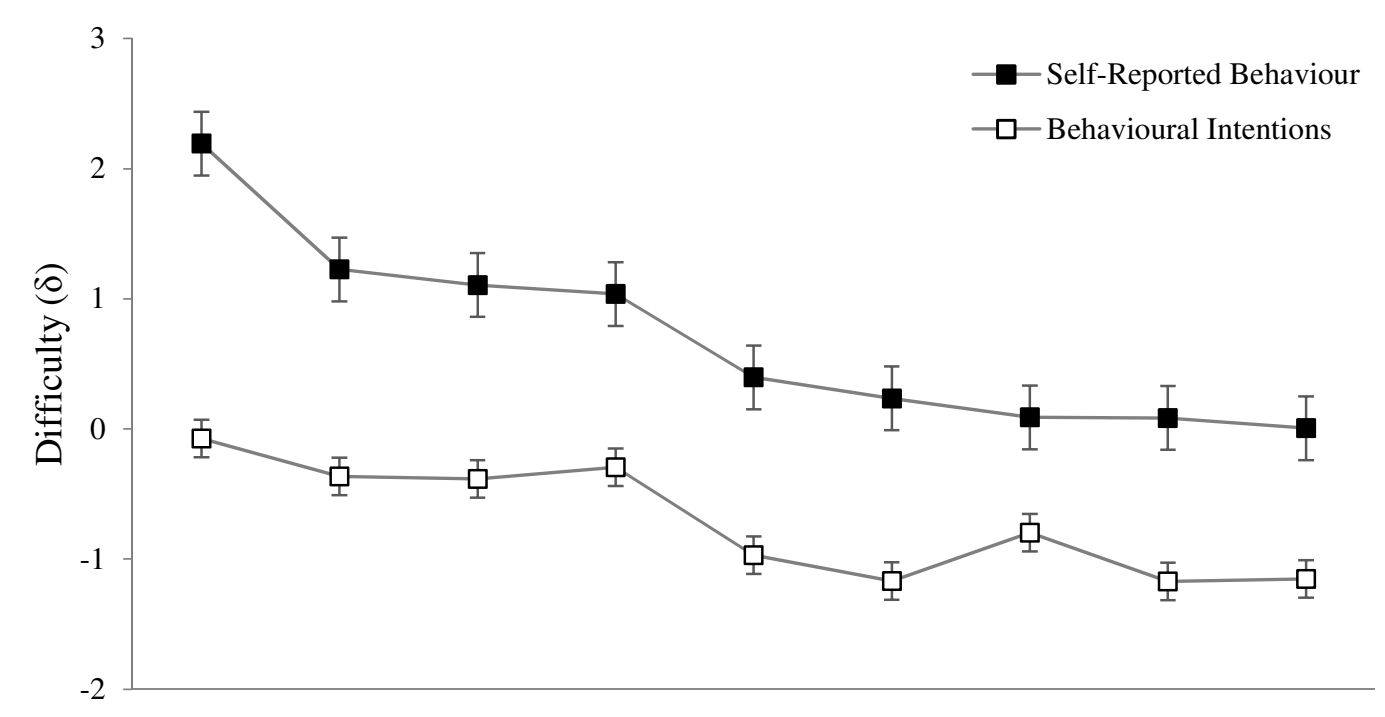

Figure 1. Graphical depiction of difficulty estimates for self-reported behaviors and corresponding statements of behavioral intention in descending order $(N=543)$. Vertical bars indicate $95 \%$ confidence intervals based on the estimation error. 


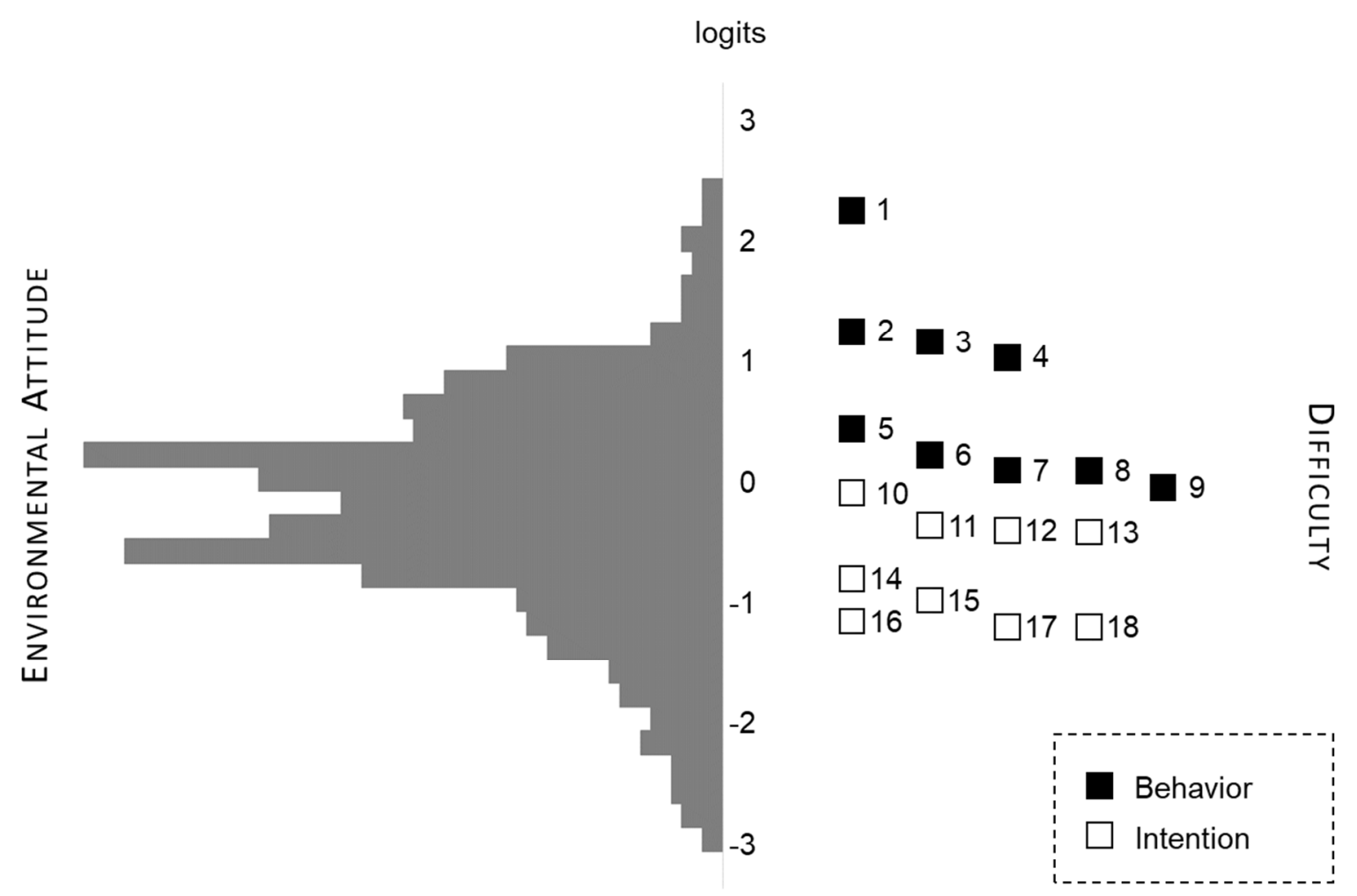

Figure 2. Item-person map of the Campbellian measure of environmental attitude. On the left side the distribution of environmental attitude in the sample is displayed. On the right side items are shown by their difficulty.

Note. For environmental attitude the mean of the five plausible values for each person is shown. Item numbers correspond to Table 1. The metric of both, environmental attitude and item difficulty, is in logits. 